\title{
Further investigation of gateway effects using the PATH
}

\section{study [version 1; peer review: 2 approved with reservations]}

\author{
Peter N Lee(i)1, John S Fry (iD2 \\ ${ }^{1}$ P.N.Lee Statistics and Computing Ltd., Sutton, Surrey, SM2 5DA, UK \\ ${ }^{2}$ Roelee Statistics Ltd, Sutton, Surrey, SM2 5DA, UK
}

\begin{tabular}{l}
\hline V1 First published: 15 Jun 2020, 9:607 \\
https://doi.org/10.12688/f1000research.24289.1 \\
Latest published: 09 Nov 2020, 9:607 \\
https://doi.org/10.12688/f1000research.24289.2 \\
\hline
\end{tabular}

\section{Abstract}

Background: Interest exists in whether youth e-cigarette use ("vaping") increases risk of initiating cigarette smoking. Using Waves 1 and 2 of the US PATH study we reported that adjustment for vaping propensity using Wave 1 variables explained about $80 \%$ of the unadjusted relationship. Here we use data from Waves 1 to 3 to avoid over-adjustment if Wave 1 vaping affected variables recorded then. Methods: Our main analysis M1 concerned Wave 2 never smokers who never vaped by Wave 1, linking Wave 2 vaping to Wave 3 smoking initiation, adjusting for Wave 1 predictors. We conducted sensitivity analyses that: excluded Wave 1 other tobacco product users; included other product use as an extra predictor; or considered propensity for smoking or any tobacco use, rather than vaping. We also conducted analyses that: adjusted for propensity as derived originally; ignored Wave 1 data; used exact age (not previously available) as a confounder rather than grouped age; attempted residual confounding adjustment by modifying predictor values using data recorded later; or considered interactions with age.

Results: In M1, adjustment removed about half the excess OR (i.e. OR-1), the unadjusted OR, 5.60 (95\% CI 4.52-6.93), becoming 3.37 (2.65-4.28), 3.11 (2.47-3.92) or 3.27 (2.57-4.16), depending whether adjustment was for propensity as a continuous variable, as quintiles, or for the variables making up the propensity score. Many factors had little effect: using grouped or exact age; considering other products; including interactions; or using predictors of smoking or tobacco use rather than vaping. The clearest conclusion was that analyses avoiding over-adjustment explained about half the excess OR, whereas analyses subject to over-adjustment explained about $80 \%$.

Conclusions: Although much of the unadjusted gateway effect results from confounding, we provide stronger evidence than previously of some causal effect of vaping, though some doubts still remain about the completeness of adjustment.

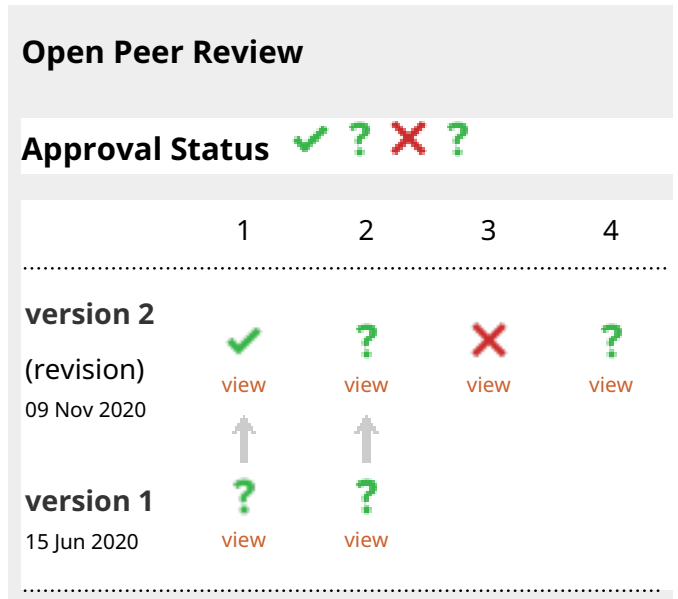

1. James Sargent, Geisel School of Medicine at Dartmouth, Lebanon, USA

2. Shu Xu ID, NYU School of Global Public Health, New York City, USA New York University, New York, USA

3. Jean Long ${ }^{D}$, New York University, New York, USA

4. Arielle S. Selya ID, New York University, New York, USA

New York University, New York, USA

Any reports and responses or comments on the article can be found at the end of the article. 


\section{Keywords}

Cigarettes, Confounding, Over-adjustment, E-cigarettes, Gateway

effects, Modelling, Propensity score

Corresponding author: Peter N Lee (PeterLee@pnlee.co.uk)

Author roles: Lee PN: Conceptualization, Funding Acquisition, Methodology, Project Administration, Supervision, Validation, Writing Original Draft Preparation, Writing - Review \& Editing; Fry JS: Data Curation, Formal Analysis, Investigation, Methodology, Software, Validation, Writing - Review \& Editing

Competing interests: Both authors are long term consultants to many tobacco companies and organizations, including the funder of this study.

Grant information: Financial support was provided by Philip Morris Products SA, through Project Agreement no. 29 with P N Lee Statistics and Computing Ltd. While some technical comments were provided by the funder on drafts of the statistical plan and this publication, the final versions remain the responsibility of the authors.

Copyright: (c) 2020 Lee PN and Fry JS. This is an open access article distributed under the terms of the Creative Commons Attribution License, which permits unrestricted use, distribution, and reproduction in any medium, provided the original work is properly cited.

How to cite this article: Lee PN and Fry JS. Further investigation of gateway effects using the PATH study [version 1; peer review: $\mathbf{2}$ approved with reservations] F1000Research 2020, 9:607 https://doi.org/10.12688/f1000research.24289.1

First published: 15 Jun 2020, 9:607 https://doi.org/10.12688/f1000research.24289.1 


\section{Abbreviations}

CI, confidence interval; OR, odds ratio; PATH, Population Assessment of Tobacco and Health.

\section{Introduction}

In youths, use of e-cigarettes ("vaping") has increased considerably in recent years in many countries (e.g. (Barrington-Trimis et al., 2016; Best et al., 2016; Miech et al., 2019)). It is generally recognized that vaping significantly reduces exposure to harmful constituents compared to smoking (National Academies of Sciences Engineering and Medicine, 2018), so one might expect risks from vaping to be much lower (Nutt et al., 2014). However, there are concerns about the rise in vaping. The concern of interest here is the possibility that vaping may encourage some individuals to start smoking who would otherwise not have done so, often referred to as the "gateway" effect. The concern that vaping may act as a gateway into smoking was originally brought sharply into focus by a 2017 meta-analysis (Soneji et al., 2017) which combined data from nine cohort studies in young people in the US which related previous vaping to later smoking initiation. It reported that, among never-smokers at baseline, ever vaping at baseline strongly predicted initiating smoking in the next 6 to 18 months, with an odds ratio (OR) of $3.62(95 \%$ confidence interval (CI) 2.42-5.41) after adjusting for various factors predictive of initiation. Similarly past 30-day vaping at baseline also predicted later 30-day cigarette use (OR 4.25, 95\% CI 2.52-7.37).

We have previously published two papers relating to the gateway effect. Our first paper (Lee et al., 2018) considered various general issues. It made a number of relevant points:

- The studies that reported that vaping significantly predicts initiation of smoking after adjusting for various other predictors, used sets of predictors that were generally quite incomplete.

- $\quad$ Residual confounding arising from the predictors being inaccurately measured was not taken account of in any of the studies.

- Adjusting more precisely may have reduced the association substantially.

- Any true gateway effect would only alter smoking prevalence modestly.

- In youths in the US and UK in 2014-2016 smoking prevalence declined more rapidly than the preceding trend would predict, contrary to what might expect if any large gateway effect existed.

- Even given the existence of some gateway effect, the introduction of e-cigarettes would still likely reduce smoking-related mortality.

Our second paper (Lee \& Fry, 2019) described results of our own analyses, based on data from Waves 1 and 2 of the Population Assessment of Tobacco and Health (PATH) study, a nationally representative longitudinal cohort study in the United States of tobacco use and how it affects the health of people. Wave 1 was conducted from 12 September 2013 to 15 December 2014, with Wave 2 the first annual follow-up. For each Wave, data are available separately for Youths (aged 12-17 years) and Adults (aged 18+ years), the Youth data including some information from the parents. Publicly available data files include extensive information on use of various types of tobacco products and on a range of variables linked to initiation of tobacco. Note that where youths become 18 between successive Waves of the survey, their data will be available in the Adult data rather than the Youth data. Also, additional youths who were under 12 at the time of Wave 1 are added into the Youth data when they reach the age of 12 at a subsequent Wave.

In our main analyses we included youths who had never smoked cigarettes by Wave 1, and had data on smoking initiation by Wave 2. We constructed a propensity score for ever e-cigarette use using variables recorded at Wave 1 and found that adjustment reduced the unadjusted OR markedly, from 5.70 (95\% CI 4.33$7.50)$ to 2.48 (1.85-3.31), 2.47 (1.79-3.42) or 1.85 (1.35-2.53), whether adjustment was made using quintiles of the propensity score, using propensity as a continuous variable, or using each variable making up the score. In sensitivity analyses we confirmed that adjustment explained most of the apparent gateway effect.

Although we found that confounding was a major factor, explaining most of the observed gateway effect, we were particularly concerned about the possibility of over-adjustment, if taking up e-cigarettes had affected the values of some of the Wave 1 predictor variables considered. At the time, we noted that the possibility of over-adjustment could be avoided using data from Waves 1,2 and 3 of the PATH study, by relating initiation of cigarette smoking at Wave 3 to vaping at Wave 2, restricting attention to those who, at Wave 1 , had never vaped, and using propensity indicators recorded at Wave 1 linked to uptake of e-cigarettes by Wave 2 .

Here we describe the results of extensive analyses conducted based on Waves 1, 2 and 3, which not only include the main analyses envisaged at the time of our earlier paper (Lee \& Fry, 2019), but also a variety of sensitivity and alternative analyses.

\section{Methods}

Some aspects of the analyses described here are the same as those described earlier (Lee \& Fry, 2019) and are not presented again here. The selection of demographic and other predictor variables is the same as before, except that in some analyses we use exact age $(12,13,14,15,16$ and 17), which could now be estimated from the age group $(12-14,15-17)$ at the three Waves and the Wave when youths became adults (18+) for the first time. Use of the person-level weights provided in the PATH study database is as before, as is the process by which a sequence of logistic regression analyses is used to develop the shorter list of demographic variables to be used in forming the propensity scores.

Our main analysis M1 is based on those with data at Waves 1, 2 and 3 who had never smoked cigarettes by Wave 2 and had never used e-cigarettes by Wave 1 . This analysis predicts Wave 3 ever smoking from Wave 2 ever e-product use, with adjustment based on Wave 1 predictors used to derive a propensity index 
for taking up e-products between Waves 1 and 2, and exact age being used in preference to grouped age. Note that, whereas in Wave 1 questions in PATH related only to e-cigarette use, in Waves 2 and 3 questions related to ever e-product use, which also included use of e-cigars, e-pipes and e-hookahs.

Associated with main analysis M1 are four sensitivity analyses (S1 to S4) which are otherwise similar, except that:

S1. Those who had ever used other tobacco products at Wave 1 are excluded;

$\mathrm{S} 2$. Ever use of other tobacco products at Wave 1 is included as an additional predictor variable;

S3. The analysis is based on a propensity score for ever cigarette smoking rather than for ever vaping; or

S4. The analysis is based on a propensity score for ever use of any tobacco product rather than for ever vaping.

Note that in our original paper (Lee \& Fry, 2019) we also presented results of a further sensitivity analysis, based on linking current vaping to current smoking. This was not repeated here as numbers of new current smokers in current vapers were very low.

Main analysis M2 is similar to M1, except that analysis adjusts for the propensity index as originally derived (Lee \& Fry, 2019), based on 12 variables recorded at Wave 1. Alternative versions of M2 substitute exact age rather than grouped age in deriving the propensity index, and/or included Wave 1 vapers in the analysis.

Main analysis M3 adjusts for a propensity index derived by linking Wave 2 predictors to Wave 2 e-product use. This is a replicate of the analysis conducted originally (Lee \& Fry, 2019), but using a different period of taking up cigarettes. Data for Wave 1 were ignored, except that where the data for a characteristic was "ever in last 12 months", Wave 1 data were used to define "ever". An alternative version of M3 replaces grouped age by exact age in deriving the propensity index.

Apart from analyses linking Wave 2 e-product use to additional cigarette smoking at Wave 3 in those who had never smoked at Wave 2, two additional analyses (A1 and A2) were also conducted.

Additional analysis A1 relates e-cigarette use at Wave 1 to cigarette smoking at Wave 2 as in our earlier publication (Lee \& Fry, 2019), but based on individuals who provided data at all three Waves. One version of this uses the same 12 variables as before to develop the propensity index, the other replaces grouped age by exact age. The OR from this analysis can be combined with that reported for main analysis M2 to give a combined estimate of the gateway effect for Wave 1 to 2 initiation and Wave 2 to 3 initiation based on the same set of variables determined at Wave 1.

Additional analysis A2 ignores Wave 2 data and relates e-cigarette use at Wave 1 to cigarette smoking at Wave 3 using the same 12 variables as before, but replacing grouped age by exact age.

Consideration of residual confounding was also taken into account for three of the analyses described above (M1, M3, A1), all involving exact age. In each case, the list of predictor variables was unaltered from that used originally, but the values of the predictor variables and of the propensity index were revised based on data available at all three Waves. For age, individual year of age at Wave 1 was used, while gender and Hispanic origin did not change between Waves. For the other variables used to form the propensity index, we used all the available data, generally choosing the response most associated with increased e-cigarette use where response varied between Waves (see Additional File Table 1, Extended data, for further details (Lee, 2020)).

For analyses M1, M3 and A1, alternative versions were also run in which the number of variables adjusted for was increased by also including interactions of age with each of the other three predictors most strongly linked to the relevant gateway effect.

\section{Software}

Relevant data were transferred for analysis to a ROELEE database, and analysed using the ROELEE program (Release 59, Build 49). All these analyses could be run using the GLM Package and the Step Function from the R Program (https://www.r-project.org/).

\section{Results}

M1: Relating initiation of cigarette smoking between Waves 2 and 3 to ever e-product use at Wave 2, with adjustment for Wave 1 predictors linked to uptake of e-cigarettes between Waves 1 and 2

Initial analyses linked exact age, four other demographic variables (gender, Hispanic origin, race and census region) and 60 other selected predictor variables to ever e-product use at Wave 2 in those who had not smoked or used e-cigarettes at Wave 1. A propensity index based on 16 variables was derived using the three step process described earlier (Lee \& Fry, 2019). Additional File Table 2 (see Extended data (Lee, 2020)) shows the steps at which different variables were eliminated from consideration, while Table 1 gives the fitted equation for the propensity index.

As shown in Table 2, adjustment for propensity removed about half the excess OR (i.e. OR-1), the unadjusted OR of $5.60(95 \%$ CI 4.52-6.93) reducing to either 3.37 (2.65-4.28) or 3.11 (2.473.92 ), depending on whether adjustment was as a continuous variable or as quintiles. A similar reduction in the OR, to 3.27 (2.574.16), was achieved by adjusting for the 16 variables individually. It can also be seen that, for the first seven variables adjusted for, the adjusted OR decreased steadily, to 3.25. Further adjustment had little or no effect, with introducing additional variables sometimes slightly increasing the estimated OR and sometimes slightly decreasing it.

Four sensitivity analyses of M1 were carried out, fuller details being given in Table 3 to Table 6 of the Additional File (see Extended data (Lee, 2020)). 


\section{Table 1. Predicting Wave 2 ever-cigarette use from 16 Wave 1 predictor variables (Main analysis M1).}

\begin{tabular}{|c|c|c|c|}
\hline Variable $^{a}$ & Levels & $\mathbf{N}$ & OR $(95 \% \mathrm{CI})$ \\
\hline \multirow[t]{6}{*}{ Exact age } & 12 & 1518 & 1.00 (base) \\
\hline & 13 & 1474 & $1.71(1.23-2.38)$ \\
\hline & 14 & 1451 & $1.97(1.43-2.71)$ \\
\hline & 15 & 1376 & $2.25(1.65-3.08)$ \\
\hline & 16 & 1188 & $2.55(1.86-3.51)$ \\
\hline & 17 & 1051 & $3.75(2.72-5.15)$ \\
\hline $\begin{array}{l}\text { Ever been curious about smoking } \\
\text { a cigarette }\end{array}$ & & & $0.86(0.76-0.97)^{b}$ \\
\hline $\begin{array}{l}\text { Think you will smoke a cigarette } \\
\text { in the next year }\end{array}$ & & & $0.59(0.48-0.71)^{c}$ \\
\hline \multirow[t]{3}{*}{$\begin{array}{l}\text { Anyone who lives with you now } \\
\text { use tobacco }\end{array}$} & $\begin{array}{l}\text { Cigarettes, cigars, } \\
\text { cigarillos, filtered cigars }\end{array}$ & 2140 & 1.00 (base) \\
\hline & $\begin{array}{l}\text { Smokeless or other } \\
\text { tobacco only }\end{array}$ & 319 & $1.73(1.26-2.37)$ \\
\hline & $\begin{array}{l}\text { No-one living in the home } \\
\text { uses tobacco }\end{array}$ & 5599 & $0.78(0.65-0.94)$ \\
\hline \multirow[t]{2}{*}{ Ever used alcohol at all } & Yes & 2483 & 1.00 (base) \\
\hline & No & 5575 & $0.53(0.45-0.62)$ \\
\hline \multirow{5}{*}{$\begin{array}{l}\text { Agree/disagree: like new and } \\
\text { exciting experiences, even if I } \\
\text { have to break the rules }\end{array}$} & Strongly agree & 285 & 1.00 (base) \\
\hline & Agree & 1252 & $0.71(0.52-0.97)$ \\
\hline & Neither agree nor disagree & 2107 & $0.64(0.47-0.87)$ \\
\hline & Disagree & 2404 & $0.38(0.28-0.53)$ \\
\hline & Strongly disagree & 2010 & $0.46(0.32-0.65)$ \\
\hline \multirow{10}{*}{$\begin{array}{l}\text { Youth's grade performance in } \\
\text { school in past } 12 \text { months }\end{array}$} & Mostly A's & 2342 & 1.00 (base) \\
\hline & A's or B's & 2849 & $1.30(1.07-1.58)$ \\
\hline & Mostly B's & 702 & $1.60(1.22-2.10)$ \\
\hline & B's or C's & 1346 & $1.47(1.17-1.85)$ \\
\hline & Mostly C's & 325 & $2.16(1.52-3.09)$ \\
\hline & C's or D's & 334 & $2.74(1.95-3.86)$ \\
\hline & Mostly D's & 45 & $2.09(0.90-4.87)$ \\
\hline & D's or F's & 71 & $2.54(1.34-4.81)$ \\
\hline & Mostly F's & 10 & $1.85(0.26-12.91)$ \\
\hline & School is ungraded & 34 & $1.80(0.54-6.06)$ \\
\hline \multirow{5}{*}{$\begin{array}{l}\text { How often you visit your } \\
\text { Facebook, Google Plus, } \\
\text { MySpace, Twitter or other }\end{array}$} & Several times a day & 2464 & 1.00 (base) \\
\hline & About once a day & 2284 & $0.67(0.56-0.80)$ \\
\hline & 3-5 days a week & 1006 & $0.73(0.58-0.92)$ \\
\hline & 1-2 days a week & 732 & $0.51(0.37-0.69)$ \\
\hline & Never & 1572 & $0.40(0.31-0.53)$ \\
\hline \multirow{4}{*}{$\begin{array}{l}\text { Agree/disagree: I think I would } \\
\text { enjoy using tobacco }\end{array}$} & Strongly agree & 18 & 1.00 (base) \\
\hline & Agree & 95 & $0.42(0.14-1.31)$ \\
\hline & Disagree & 1517 & $0.57(0.20-1.58)$ \\
\hline & Strongly disagree & 6428 & $0.35(0.12-1.01)$ \\
\hline
\end{tabular}




\begin{tabular}{|c|c|c|c|}
\hline Variable $^{a}$ & Levels & $\mathbf{N}$ & OR $(95 \% \mathrm{Cl})$ \\
\hline \multirow[t]{2}{*}{ Hispanic origin } & Hispanic & 2332 & 1.00 (base) \\
\hline & Not Hispanic & 5726 & $0.67(0.57-0.79)$ \\
\hline \multirow{4}{*}{$\begin{array}{l}\text { Became very distressed when } \\
\text { something reminded of past }\end{array}$} & Past month & 1940 & 1.00 (base) \\
\hline & 2-12 months & 1137 & $0.86(0.70-1.07)$ \\
\hline & Over a year & 906 & $0.71(0.55-0.92)$ \\
\hline & Never & 4075 & $0.74(0.62-0.89)$ \\
\hline \multirow{2}{*}{$\begin{array}{l}\text { Cigarettes or tobacco might be } \\
\text { available to youth at parent or } \\
\text { guardian's home }\end{array}$} & Yes & 1057 & 1.00 (base) \\
\hline & No & 7001 & $0.65(0.52-0.80)$ \\
\hline \multirow{9}{*}{$\begin{array}{l}\text { Money received in total during an } \\
\text { average week }\end{array}$} & None & 2771 & 1.00 (base) \\
\hline & Less than $\$ 1$ & 331 & $1.34(0.91-1.96)$ \\
\hline & $\$ 1$ to $\$ 5$ & 1234 & $1.26(0.99-1.61)$ \\
\hline & $\$ 6$ to $\$ 10$ & 1019 & $1.40(1.10-1.79)$ \\
\hline & $\$ 11$ to $\$ 20$ & 1289 & $1.42(1.14-1.77)$ \\
\hline & $\$ 21$ to $\$ 50$ & 751 & $1.36(1.06-1.75)$ \\
\hline & $\$ 51$ to $\$ 100$ & 337 & $1.53(1.11-2.10)$ \\
\hline & $\$ 101$ to $\$ 150$ & 160 & $2.02(1.33-3.06)$ \\
\hline & $\$ 151$ or more & 166 & 1.96 (1.29-2.99) \\
\hline \multirow{4}{*}{$\begin{array}{l}\text { Last time } 2+\text { times: had a hard } \\
\text { time paying attention at school, } \\
\text { work or home }\end{array}$} & Past month & 2700 & 1.00 (base) \\
\hline & 2-12 months & 1402 & $0.75(0.62-0.92)$ \\
\hline & Over a year & 819 & $0.84(0.64-1.09)$ \\
\hline & Never & 3137 & $0.72(0.59-0.87)$ \\
\hline \multirow[t]{4}{*}{ Number of times seen Movie 4} & Never & 6839 & 1.00 (base) \\
\hline & Once & 858 & $0.91(0.73-1.11)$ \\
\hline & Twice & 190 & $1.24(0.83-1.86)$ \\
\hline & 3 or more times & 171 & $1.91(1.29-2.82)$ \\
\hline Think you will try a cigarette soon & & & $1.99(1.17-3.37)^{d}$ \\
\hline \multicolumn{4}{|c|}{$\begin{array}{l}\text { Note: The model is based on } 8058 \text { youths with data on all } 16 \text { predictors who neither smoked nor used } \\
\text { e-cigarettes at Wave } 1 .\end{array}$} \\
\hline \multicolumn{4}{|c|}{ a The variables are shown in order of their inclusion into the model. } \\
\hline \multicolumn{4}{|c|}{ b The OR is per unit of the graded variable which represents decreasing curiosity. } \\
\hline \multicolumn{4}{|c|}{${ }^{\circ}$ The OR is per unit of the graded variable which represents decreasing likelihood. } \\
\hline \multicolumn{4}{|c|}{$\begin{array}{l}\text { "The OR is per unit of the graded variable which represents decreasing likelihood, with those originally } \\
\text { entered as missing because they thought that they would not smoke a cigarette in the next year scored as } \\
\text { "definitely not" (Level 4). }\end{array}$} \\
\hline
\end{tabular}

Compared to M1, S1 excluded those who had ever used products other than cigarettes or e-cigarettes at Wave 1, both in the construction of the propensity index and in estimating the gateway effect. Whereas M1 involved 8260 youths, of which 409 initiated smoking between Waves 2 and 3, S1 involved 7945, of which 359 took up smoking. The propensity index developed for S1 involved all the 16 variables shown in Table 2, except for "Number of times seen Movie 4" and "Think you will try a cigarette soon". Here, the pattern of results is similar to that for Table 2, with the unadjusted OR of 5.66 (95\% CI 4.49-7.13) reducing to either 3.45 (2.67-4.46), 3.24 (2.53-4.15), or 3.23 (2.49-4.18), depending on whether adjustment was made for propensity as a continuous variable, propensity as quintiles, or all the 14 variables individually. 
Table 2. Relating Wave 3 ever smoking to Wave 2 ever e-product use (Main analysis M1).

\begin{tabular}{|l|l|}
\hline Adjustment variables & OR (95\% Cl) \\
\hline None & $5.60(4.52-6.93)$ \\
\hline Propensity score as quintiles & $3.11(2.47-3.92)$ \\
\hline Propensity score as a continuous variable & $3.37(2.65-4.28)$ \\
\hline Exact age & $4.87(3.91-6.06)$ \\
\hline + Ever been curious about smoking a cigarette & $4.27(3.41-5.34)$ \\
\hline + Think you will smoke a cigarette in the next year & $3.84(3.06-4.82)$ \\
\hline + Anyone who lives with you now use tobacco & $3.73(2.97-4.69)$ \\
\hline + Ever used alcohol at all & $3.48(2.76-4.38)$ \\
\hline + Agree/disagree: Like new and exciting experiences even if I have to break the rules & $3.39(2.68-4.28)$ \\
\hline + Youth's grade performance in school in past 12 months & $3.25(2.57-4.12)$ \\
\hline + How often you visit your Facebook, Google Plus, MySpace, Twitter or other & $3.17(2.50-4.01)$ \\
\hline + I think I would enjoy using tobacco & $3.17(2.50-4.02)$ \\
\hline + Hispanic origin & $3.22(2.54-4.09)$ \\
\hline + Last time a significant problem with: becoming very distressed when something reminded of past & $3.19(2.51-4.05)$ \\
\hline + Cigarettes or tobacco might be available to youth at parent or guardian's home & $3.17(2.50-4.02)$ \\
\hline + Money received in total during an average week & $3.25(2.56-4.13)$ \\
\hline + Last time 2+ times: Had a hard time paying attention at school, work or home & $3.22(2.53-4.09)$ \\
\hline + Number of times seen Movie 4 & $3.28(2.57-4.17)$ \\
\hline + Think you will try a cigarette soon & $3.27(2.57-4.16)$ \\
\hline
\end{tabular}

Notes: The table shows the effects of adjustment based on the Wave 1 predictors used to derive a propensity index for taking up e-products between Wave 1 and 2. The analyses are based on those with data at Waves 1, 2 and 3 who had never smoked cigarettes by Wave 2 and had never used e-cigarettes by Wave 1. Between Waves 2 and 3261/7367 (3.54\%) of never users of e-products at Wave 2 took up smoking, while 148/893 (16.57\%) of ever users did so. For individuals who were 16-17 at Wave 1, adult data were used to determine e-product use and cigarette smoking at later Waves. The table includes the results of a stepwise regression based on successively including the most significant adjustment variables, given that ever e-product use at Wave 2 was included in the model.

Table 3. Relating Wave 3 ever smoking to Wave 2 ever e-product use (Main analysis M2).

\begin{tabular}{|l|l|l|}
\hline \multicolumn{2}{|l|}{$\begin{array}{l}\text { Adjustment variables } \\
\text { None }\end{array}$} & OR (95\% CI) \\
\hline \multicolumn{2}{|l|}{ Propensity score as quintiles } & $5.74(4.62-7.13)$ \\
\hline \multicolumn{2}{|l|}{ Propensity score as continuous variable } & $3.54(2.81-4.45)$ \\
\hline Age range & & $4.53(3.62-5.68)$ \\
\hline+ & Ever used alcohol at all & $5.20(4.17-6.49)$ \\
\hline+ & Ever been curious about smoking a cigarette & $4.45(3.54-5.58)$ \\
\hline+ & Think you will smoke a cigarette in the next year & $4.10(3.26-5.16)$ \\
\hline+ & Agree/disagree: Prefer friends who are exciting and unpredictable & $3.70(2.94-4.68)$ \\
\hline+ & Reaction if parent/guardian found you using tobacco & $3.65(2.89-4.61)$ \\
\hline+ & Gender & $3.64(2.88-4.60)$ \\
\hline+ & Agree/disagree: I think I would enjoy using tobacco & $3.63(2.87-4.58)$ \\
\hline+ & Agree/disagree: Some products are safer than others & $3.63(2.87-4.59)$ \\
\hline+ & Ever used prescription drug not prescribed to you: Ritalin or Adderall & $3.63(2.87-4.59)$ \\
\hline+ & Has a Facebook, Google Plus, MySpace, Twitter or other social networking & $3.67(2.90-4.64)$ \\
\hline+ & Anyone who lives with you now use tobacco & $3.45(2.79-4.47)$ \\
\hline
\end{tabular}

Notes: The table shows the effects of adjustment based on the same Wave 1 predictors as used in our original paper (Lee \& Fry, 2019). The analyses are based on those with data at Waves 1, 2 and 3 who had never smoked cigarettes by Wave 2 and had never used e-cigarettes by Wave 1. Between Waves 2 and 3, 249/7133 (3.49\%) of never users of e-products at Wave 2 took up smoking, while 146/880 (16.59\%) of ever users did so. For individuals who were 16-17 at Wave 1, adult data were used to determine e-product use and cigarette smoking at later Waves. The table includes the results of a stepwise regression based on successively including the most significant adjustment variables, given that ever e-product use at Wave 2 was included in the model. 
Compared to M1, the only difference for S2 was that ever smoked other tobacco products at Wave 1 was added to the 16 variables used in M1 to make up the propensity score, and was forced into the regression models. Starting with the same unadjusted OR as M1, the adjusted ORs were very similar; 3.37 (2.64-4.29), 3.07 (2.44-3.87) and 3.20 (2.50-4.08), after adjustment for propensity (continuous), propensity (quintiles), or all the individual variables.

Whereas M1 (and S1 and S2) adjusted for variables found to be predictive of initiating e-product use at Wave 2, S3 adjusted for variables predictive of cigarette smoking. Here, the final model included 27 variables. The unadjusted OR of $5.65(95 \%$ CI 4.55-7.01) slightly differed from that in $\mathrm{M} 1$ as the individuals considered had to have non-missing data on 27 variables rather than 16 . However, the overall effect of adjustment was again similar, with the OR reducing to 3.28 (2.56-4.22) after adjustment for all 27 variables. As for M1, adjustment for the first four variables had the most effect. Adjustment for the first seven variables reduced the OR to 3.26 (2.57-4.13), similar to the OR after adjustment for all 27 . Propensity adjustment was not carried out in S3.

Compared to M1, S4 adjusted for variables predictive of take-up of any tobacco product between Waves 1 and 2. Here, the propensity index was based on 18 variables, with the unadjusted OR of 5.74 (4.55-7.23) reducing to 3.31 (95\% CI 2.56-4.28), 3.19 (2.48-4.09), or 3.21 (2.47-4.18), after adjustment for propensity (continuous), propensity (quintiles), or all the individual variables. Adjustment for all 18 variables had a similar effect to adjustment for the most important 10 variables, where the OR was $3.20(2.47-4.14)$.

M2: Relating initiation of cigarette smoking between Waves 2 and 3 to ever e-product use at Wave 2, with adjustment for the same Wave 1 predictors as previously reported (Lee \& Fry, 2019)

Here, instead of deriving the Wave 1 predictors linked to uptake of e-cigarettes between Waves 1 and 2, analysis M2 uses the same set of Wave 1 predictors used in our earlier work (Lee \& Fry, 2019), the results being shown in Table 3. Here, the unadjusted OR of 5.74 (95\% CI 4.62-7.13) reduced to 3.54 (2.81-4.45) after adjustment for propensity as quintiles and to 3.45 (2.72-4.37) after adjusting for the individual variables. While adjustment here removed about half the excess OR, the reduction was less, to 4.53 (3.62-5.68), after adjustment for propensity as a continuous variable. The reductions were similar if exact age rather than age group was included in the list of variables. Here, the unadjusted OR was reduced to 3.51 (2.79-4.41) after adjustment for propensity as quintiles, 4.59 (3.66-5.74) after adjustment for propensity as a continuous variable, and 3.39 (2.67-4.30) after adjustment for the individual variables.

Similar analyses were also run that did not exclude those who had used e-cigarettes by Wave 1 . This increased the number of ever e-product users who took up smoking from 146 to 201, and slightly increased the unadjusted OR to 5.95 (4.89-7.23). However, the pattern of decline following adjustment was quite similar. For example, the OR adjusted for the individual variables reduced to $3.31(2.65-4.12)$ using grouped age and to 3.26 (2.62-4.06) using exact age.

M3: Relating initiation of cigarette smoking between Waves 2 and 3 to ever e-product use at Wave 3 , with adjustment for Wave 2 predictors

As noted in the Methods section, M3 is essentially a replicate of our earlier work (Lee \& Fry, 2019), but using a different period of introduction of cigarettes. The propensity score developed was based on 18 variables, using age group or exact age as alternatives. The results, shown in Table 4, indicate that, as earlier (Lee \& Fry, 2019), a large proportion of the unadjusted association can be explained by adjustment. The largest proportion was explained by adjusting for the 18 variables making up the propensity score, with the unadjusted OR of $6.70(95 \%$ CI 5.40-8.32) reducing to 2.25 (1.74-2.91) or 2.75 (1.75-2.93) depending on whether the list of variables included age range or exact age. However, most of this reduction could be explained by adjustment for propensity.

Combining the Wave 2 to 3 results shown in Table 4 with the Wave 1 to 2 results reported earlier (Lee \& Fry, 2019) by fixedeffect meta-analysis gives an unadjusted OR of 6.30 (5.31-7.46), which is reduced to $2.65(2.24-3.18), 2.53(2.07-3.10)$ or 2.08 (1.70-2.54) depending on whether adjustment is for propensity (quintiles), propensity (continuous) or all the variables making up the propensity score. This represents reductions in the excess OR of, respectively, $68.9 \%, 71.1 \%$ or $79.8 \%$.

\section{A1: Relating initiation of cigarette smoking between Waves 1 and 2 to ever e-cigarette use at Wave 1 , based on individuals who provided data at all three Waves \\ Table 5 summarizes the main results of these analyses and com- pares them with those reported earlier (Lee \& Fry, 2019). While the original analyses were based on 9423 youths, 421 of whom initiated smoking, the new analyses were based on 8700 youths, 389 of whom initiated smoking. As can be seen, the results in the original analysis, based on grouped age, were similar to those from the new analyses, whether grouped or exact age was used.}

The results from analysis A1 for grouped age may theoretically be combined with those from analysis M2 shown in Table 3, as they both use the Wave 1 predictors from our original paper (Lee \& Fry, 2019), with exact age replacing grouped age, and are both based on individuals with data at all three Waves. However, as illustrated by the results adjusted for all 12 variables, where the ORs are 3.45 (95\% CI 2.72-4.37) from Table 3 and 1.97 (1.42-2.73) from Table 5, these estimates are heterogeneous $(\mathrm{p}<0.001)$, providing a random-effects combined estimate of 2.64 (1.52-4.57).

\section{A2: Relating Wave 3 ever smoking to Wave 1 e-cigarette} use, ignoring Wave 2 data

This analysis is similar to that reported originally (Lee \& Fry, 2019) but relates to a longer follow-up period, and uses exact rather than grouped age. The results of this analysis, shown in Table 6, 
Table 4. Relating Wave 3 ever smoking to Wave 2 ever e-product use (Main analysis M3).

\begin{tabular}{|c|c|c|}
\hline Adjustment variables & $\begin{array}{l}\text { Using age group } \\
\text { OR }(95 \% \mathrm{Cl})\end{array}$ & $\begin{array}{l}\text { Using exact age } \\
\text { OR }(95 \% \mathrm{Cl})\end{array}$ \\
\hline None & $6.70(5.40-8.32)$ & $6.70(5.40-8.32)$ \\
\hline Propensity score as quintiles & $2.77(2.19-3.50)$ & $2.74(2.17-3.48)$ \\
\hline Propensity score as a continuous variable & $2.57(1.98-3.33)$ & $2.60(2.00-3.36)$ \\
\hline Age range & $5.78(4.62-7.22)$ & - \\
\hline Exact age & - & $5.45(4.36-6.83)$ \\
\hline + Last time a significant problem with: feeling very trapped, lonely, sad, blue, depressed & $5.22(4.17-6.54)$ & $4.95(3.94-6.21)$ \\
\hline + Reaction if parent/guardian found you using tobacco & $4.89(3.89-6.14)$ & $4.66(3.70-5.87)$ \\
\hline + Money received in total during an average week & $4.65(3.69-5.86)$ & $4.52(3.59-5.71)$ \\
\hline+ Number of times seen Movie 3 & $4.31(3.41-5.44)$ & $4.20(3.32-5.31)$ \\
\hline + Number of times seen Movie 4 & $4.12(3.25-5.21)$ & $4.02(3.18-5.10)$ \\
\hline + Ever been curious about smoking a cigarette & $3.45(2.71-4.38)$ & $3.36(2.64-4.28)$ \\
\hline + Think you will smoke a cigarette in the next year & $2.89(2.26-3.70)$ & $2.86(2.24-3.66)$ \\
\hline + Ever used alcohol at all & $2.63(2.05-3.37)$ & $2.63(2.05-3.38)$ \\
\hline + In past 12 months, youth's grade performance at school & $2.51(1.95-3.22)$ & $2.51(1.95-3.23)$ \\
\hline + Agree/disagree: using tobacco would help me calm down when I am angry & $2.43(1.89-3.12)$ & $2.43(1.89-3.13)$ \\
\hline + How often you visit your social media accounts & $2.43(1.88-3.12)$ & $2.45(1.90-3.15)$ \\
\hline+ Would smoke if one of your friends offered you one & $2.37(1.84-3.06)$ & $2.39(1.86-3.09)$ \\
\hline + Anyone who lives with you now use tobacco & $2.34(1.81-3.02)$ & $2.36(1.83-3.04)$ \\
\hline+ Think you will try a cigarette soon & $2.33(1.81-3.01)$ & $2.35(1.82-3.03)$ \\
\hline + Agree disagree: some tobacco products are safer than others & $2.30(1.78-2.97)$ & $2.32(1.79-2.99)$ \\
\hline + Youth has a curfew or set time to be home on school nights & $2.29(1.77-2.95)$ & $2.30(1.78-2.98)$ \\
\hline + Ever used prescription drug not prescribed to you: Ritalin or Adderall & $2.25(1.74-2.91)$ & $2.27(1.75-2.93)$ \\
\hline
\end{tabular}

Notes: The table shows the effects of adjustment based on Wave 2 predictors linked to use of e-products in Wave 2. The analyses are based on those with data at Waves 2 and 3 ignoring data from Wave 1. Between Waves 2 and 3,228/8233 (2.77\%) of never users of e-products at Wave 2 took up smoking, while 145/949 (15.28\%) of ever users did so. For individuals who were 17 at Wave 2, adult data were used to determine cigarette smoking at Wave 3. The table includes the results of a stepwise regression based on successively including the most significant adjustment variables, given that ever e-product use at Wave 2 was included in the model. The first set of ORs is based on a model including age group, while the second is based on a model including exact age.

Table 5. Relating Wave 2 ever smoking to Wave 1 ever e-cigarette use - original (Lee \& Fry, 2019) and A1 ORs.

\begin{tabular}{|l|l|l|l|}
\hline Adjustment variables & Data on two Waves & Data on all three Waves \\
\hline & & & \\
\hline & Originally reported OR (95\% CI) & Grouped age OR (95\% CI) & Exact age OR (95\% CI) \\
\hline None & $5.70(4.33-7.50)$ & $5.99(4.52-7.95)$ & $5.99(4.52-7.95)$ \\
\hline Propensity score as quintiles & $2.48(1.85-3.31)$ & $2.65(1.96-3.58)$ & $2.59(1.92-3.50)$ \\
\hline Propensity score as continuous variable & $2.47(1.79-3.42)$ & $2.67(1.92-3.72)$ & $2.64(1.89-3.68)$ \\
\hline Grouped age & $4.81(3.64-6.35)$ & $5.04(3.78-6.72)$ & - \\
\hline Exact age & - & - & $4.81(3.60-6.42)$ \\
\hline+11 further variables & $1.85(1.35-2.53)$ & $1.97(1.42-2.73)$ & $1.98(1.43-2.75)$ \\
\hline
\end{tabular}

Notes: Each set of ORs is based on those who had never smoked cigarettes by Wave 1. The first analysis is as summarized in Table 1. The last two analyses only exclude those without data at Wave 3. 
Table 6. Relating Wave 3 ever smoking to Wave 1 ever e-cigarette use using exact age.

\begin{tabular}{|c|c|c|}
\hline \multicolumn{2}{|c|}{ Adjustment variables } & OR $(95 \% \mathrm{Cl})$ \\
\hline \multicolumn{2}{|c|}{ None } & $5.65(4.50-7.10)$ \\
\hline \multicolumn{2}{|c|}{ Propensity score as quintiles } & $2.48(1.95-3.16)$ \\
\hline \multicolumn{2}{|r|}{ Propensity score as continuous variable } & $2.61(2.00-3.40)$ \\
\hline \multicolumn{2}{|c|}{ Exact age } & $4.69(3.71-5.93)$ \\
\hline+ & 11 further variables & $1.97(1.51-2.56)$ \\
\hline \multicolumn{3}{|c|}{$\begin{array}{l}\text { Notes: The table shows the effects of adjustment based on the same Wave } 1 \\
\text { predictors as used in our original paper (Lee \& Fry, 2019) but replacing age } \\
\text { range by exact age. The set of ORs is based on those with data at Waves } \\
1,2 \text { and } 3 \text { who had never smoked cigarettes by Wave } 1 \text {. Between Waves } 1 \\
\text { and } 3,716 / 8334(8.59 \%) \text { of never users of e-cigarettes at Wave } 1 \text { took up } \\
\text { smoking, while } 123 / 366 \text { (33.61\%) of ever users did so. The table includes } \\
\text { the results of a stepwise regression based on successively including the } \\
\text { most significant adjustment variables, given that ever e-product use at Wave } \\
1 \text { was included in the model. }\end{array}$} \\
\hline
\end{tabular}

are quite similar to those shown in Table 5. Again, an unadjusted OR is markedly reduced by adjusting for propensity, whether as quintiles or as a continuous variable, and is further reduced by adjusting for all the 12 individual variables considered.

\section{Attempting to account for residual confounding}

Table 7 summarizes the main results shown in Table 2 for main analysis M1, which make no allowance for residual confounding, and compares them with the results of an analysis using the same list of predictor variables, but with values modified in an attempt to adjust for residual confounding. As can be seen, markedly more of the unadjusted association was explained when allowance for residual confounding was made, with the adjusted ORs in the range 2.36 to 2.46 when allowance was made, compared with 3.11 to 3.37 when it was not. Note that the unadjusted ORs in the two sets of results vary slightly, as missing values in some individuals in the original analyses were replaced by estimates taken from other Waves.

While allowance for residual confounding has quite a marked effect for analysis M1, the analysis which avoided the possibility of over-adjustment, it did not for analyses M3 and A2, which did not avoid this possibility. Detailed results are shown in Table 7 and Table 8 in the Additional File (see Extended data (Lee, 2020)).

Investigating whether introducing some interactions explains more of the gateway effect

Versions of analyses M1, M3 and A1 were also seen, in which the number of variables adjusted for was extended by also including interactions of age with each of the other three predictors most strongly linked to the gateway effect. For analysis M1, allowance for these interactions had virtually no effect, the original estimate of 3.27 (95\% CI 2.57-4.16) shown in Table 2 without including interactions changing to 3.26
Table 7. Effect of allowance for residual confounding in main analysis M1.

\begin{tabular}{|l|l|l|}
\hline Adjustment variables & $\begin{array}{l}\text { M1 - no allowance } \\
\text { OR (95\% Cl) }\end{array}$ & $\begin{array}{l}\text { M1 - allowance } \\
\text { OR (95\% Cl) }\end{array}$ \\
\hline None & $5.60(4.52-6.93)$ & $5.65(4.58-6.98)$ \\
\hline $\begin{array}{l}\text { Propensity score as } \\
\text { quintiles }\end{array}$ & $3.11(2.47-3.92)$ & $2.40(1.91-3.02)$ \\
\hline $\begin{array}{l}\text { Propensity score as a } \\
\text { continuous variable }\end{array}$ & $3.37(2.65-4.28)$ & $2.46(1.93-3.14)$ \\
\hline $\begin{array}{l}\text { All 16 variables } \\
\text { individually }\end{array}$ & $3.27(2.57-4.16)$ & $2.36(1.85-3.02)$ \\
\hline
\end{tabular}

Notes: The "no allowance" results correspond to those in Table 6.

The analyses are based on those with data at Waves 1,2 and 3 who had never smoked cigarettes by Wave 2 and had never used e-cigarettes by Wave 1. Between Waves 2 and 3 261/7367 (3.54\%) of never users of eproducts at Wave 2 took up smoking, while 148/893 (16.57\%) of ever users did so in the population considered in the "no allowance" analyses The corresponding figures in the "allowance" analyses were 267/7682 (3.48\%) and $150 / 915$ (16.39\%). For individuals who were $16-17$ at Wave 1 , adult data were used to determine e-product use and cigarette smoking at later Waves. The table includes the results of a stepwise regression based on successively including the most significant adjustment variables, given that ever e-product use at Wave 2 was included in the model.

(2.55-4.15) when interactions were included in the model. For analysis M3, the estimate changed only from 2.27 (1.75-2.93) to 2.35 (1.81-3.05), while for analysis A1, it changed from 1.98 $(1.43-2.75)$ to $2.06(1.48-2.88)$.

\section{Summary of results}

Table 8 summarizes the results from 18 of the analyses described above, expressing the extent to which adjustment explained the unadjusted $\mathrm{OR}$ using the statistic $100 \mathrm{x}\left(\mathrm{OR}_{\mathrm{U}}-\mathrm{OR}_{\mathrm{A}}\right)$ / 


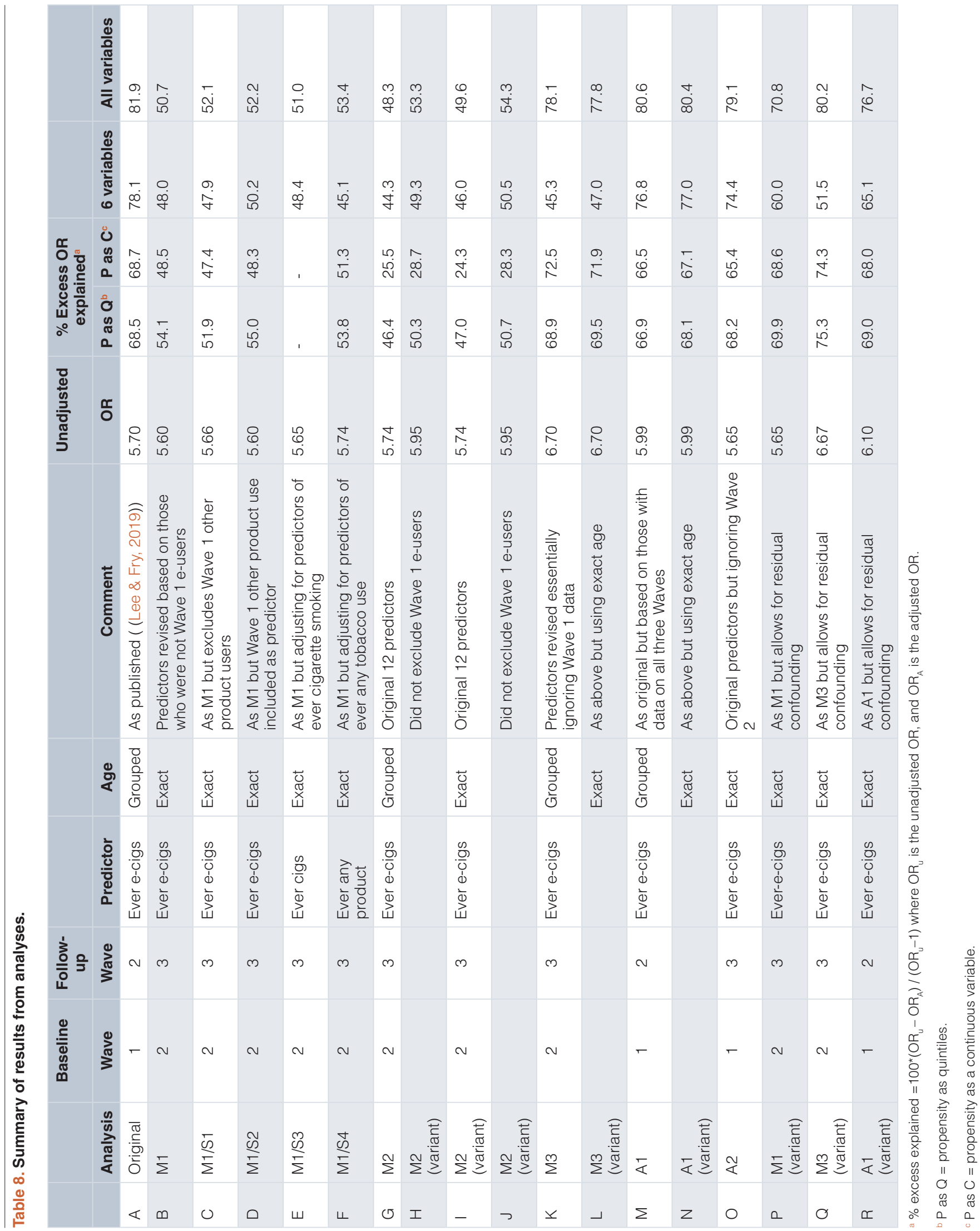


$\left(\mathrm{OR}_{U}-1\right)$ where $\mathrm{OR}_{U}$ is the unadjusted $\mathrm{OR}$, and $\mathrm{OR}_{\mathrm{A}}$ is the adjusted OR. The most obvious impression from the table is that the results largely fall into two groups.

Results from the original analysis and for analyses M3, A1 and $\mathrm{A} 2$ (rows $\mathrm{A}, \mathrm{K}$ to $\mathrm{O}$, and $\mathrm{Q}$ to $\mathrm{R}$ of Table 8) all show that as much as about $80 \%$ of the unadjusted excess OR can be explained by adjustment for the full set of variables in the model, with somewhat less, typically about $70 \%$, explained using propensity as quintiles or as a continuous variable.

In contrast, results from virtually all of analyses M1 and M2 (rows B to K) show that only about $50 \%$ of the unadjusted excess OR can be explained by adjustment for the full set of variables, with propensity as quintiles giving generally similar results.

The difference between these two groups is that the first set of results are subject to the problem of over-adjustment, with the values of the predictors used possibly having been affected by having used e-cigarettes. This is mainly so where the baseline Wave was Wave 1, but was also true for analysis M3 where Wave 1 data were essentially ignored. In contrast, the second set of results avoided over-adjustment by considering followup from Wave 2 to 3 , with predictors based on Wave 1 data in youths who had never used e-cigarettes. However, in this second set of results the variables used were not as up-to-date as in the first analyses.

The variant analysis of M1, allowing for residual confounding (row P), gives an intermediate result, with about $70 \%$ of the excess risk being explained, whether by the full set of variables or by propensity. This analysis, however, does not avoid the problem of over-adjustment as it incorporates some information from Waves where individuals were already using e-cigarettes.

It is clear from Table 8 that many of the variables studied had little effect on the pattern of results. These included use of grouped or exact age, taking into account use of other products, and using predictors of cigarette smoking or any tobacco use rather than predictors of e-cigarette use.

Two other conclusions may be drawn from Table 8 . One is that adjustment for propensity as quintiles or as a continuous variable generally gives very similar results, with the exception of analysis M2 and its variants, where propensity as a continuous variable explained substantially less of the unadjusted excess OR. Inspection of the detailed modelling results showed that, whereas in other analyses, the logarithm of the OR increased fairly linearly with quintiles of propensity, in the case of analysis M2 and its variants it did not. Thus, in M1 for example, the $\log$ ORs by quintile were $0,0.73,1.11,1.66$ and 2.52 , while in M2 they were $0,0.21,0.96,1.51$ and 2.19 , with very little rise between quintiles 1 and 2 .

The other is that adjustment for the first six variables in the model generally explained a very substantial part of the unadjusted excess OR explained by the full set. Though this was not true for analysis M2, it was still true that adjustment for the last eight or nine variables explained far less of the excess OR than did the first eight or nine.

\section{Discussion}

In our publication based on Waves 1 and 2 (Lee \& Fry, 2019) our analyses showed that an unadjusted estimate of the gateway effect 5.70 (85\% CI 4.33-7.50) could be considerably reduced by adjustment, to $1.59(1.14-2.20)$ in the most striking case. Because of the marked reduction in the OR following adjustment, and the possibility of incomplete control for confounding we regarded it as "unclear whether prior vaping actually increases uptake of cigarette smoking". However, we did note the possibility of over-adjustment, with vaping at Wave 1 possibly having affected the recorded values of some of the variables used for adjustment.

At that time we noted that this possibility of over-adjustment could be addressed in analyses relating initiation of cigarette smoking at Wave 3 to vaping at Wave 2, restricting attention to those youths who, at Wave 1 , had never vaped, and using adjustment variables recorded at Wave 1 . This we have done in the analyses reported here, and our major finding is that adjustment reduced the excess risk far less, by only about $50 \%$ rather than about $80 \%$, in our main analysis M1.

While these results more strongly support the existence of a true gateway effect of taking up vaping, there must still remain doubt about its magnitude. One reason is that predictors recorded a year before the baseline may not fully account for the characteristics of the youth at the start of follow-up. A second reason is that, although the PATH study records data on a whole range of possibly relevant characteristics, there may be some relevant predictors not considered. A third reason is that the answers to some of the questions may have been inaccurately measured. We have attempted to address this problem of residual confounding by amending values of predictors recorded at Wave 1 to take into account data recorded at later Waves. However, this problem re-introduces the problem of over-adjustment as Wave 2 and 3 values may have been affected by vaping. Theoretically, one could use data from Waves 1 to 4 , using data for Waves 1 and 2 from youths who have never vaped to produce more accurate estimates of the predictors to use for a study of gateway effects between Waves 3 and 4 . But this would add to the problem of using predictors recorded some time before follow-up.

Since the time that we published our earlier analysis (Lee \& Fry, 2019) and our paper on general considerations relating to vaping as a possible gateway into cigarette smoking (Lee et al., 2018) a number of other authors have presented evidence from prospective studies (Bold et al., 2018; Chien et al., 2019; Kinnunen et al., 2019; Morgenstern et al., 2018; Pénzes et al., 2018; Primack et al., 2018; Treur et al., 2018). The studies vary in the extent to which potential confounding variables have been adjusted for, with large OR estimates tending to be reported in studies with more limited control. Thus, a study in the Netherlands (Treur et al., 2018), which adjusted only for 
sex, age education and a single indicator of propensity to smoke, reported an OR of 11.90 (95\% CI 3.36-42.11) for the relationship between ever use of e-cigarettes with nicotine and initiation of cigarette smoking during follow-up. Also, a study in the US (Bold et al., 2018), which adjusted only for demographic variables and use of other tobacco products, reported ORs of 7.08 (2.34-21.42) and 3.87 (1.86-2.06) depending on the follow-up period studied, while another US study (Pénzes et al., 2018), with limited control for confounding variables, reported an OR of 3.57 (1.96-6.45). Apart from a US study (Primack et al., 2018), which reported an OR of 6.8 (1.7-28.3), following adjustment for ten covariates independently associated with initiation of smoking, most of the other studies that appear to have better control for confounding gave lower estimates. These included a study in Taiwan (Chien et al., 2019), which reported an OR of 2.14 (1.66-2.75), a study in Germany (Morgenstern et al., 2018), which reported an OR of 2.18 (1.65-2.87) and a study in Finland (Kinnunen et al., 2019), which reported that adjustment reduced the OR from 11.52 (4.91-26.56) to 2.92 (1.09-7.85). Notably, a study in Great Britain (East et al., 2018) reported an OR of 11.89 (3.56-39.72) estimated using the usual logistic method, but a reduced value of 1.34 (1.05-1.72) using causal mediation analysis.

Generally our results are consistent with the literature in confirming that a substantial proportion, but not all, of the observed association between e-cigarette use and subsequent initiation of cigarette smoking can be explained by adjustment for factors linked to susceptibility to tobacco. However, large cohort studies with high quality, accurate, data on a wide range of predictive factors recorded at regular intervals will be needed to gain better insight into the magnitude of any true causal effect of vaping. The PATH study with its multiple Waves and comprehensive questionnaire should prove more and more useful in the future.

There are, in theory, various effects of e-cigarettes (Lee et al., 2018). Beneficial effects occur when individuals who would have continued to smoke take up vaping instead, and when vaping helps smokers to quit or reduce cigarette consumption. Adverse effects, apart from when vaping encourages individuals to start smoking, would occur if smokers who intended to quit switch instead to vaping, or if smokers add vaping to their usual consumption of cigarettes. When trying to estimate the health impact of e-cigarettes, one must consider all these effects.
By using data from three Waves of the PATH study, the analyses of the gateway effect reported here improve on those reported earlier (Lee \& Fry, 2019) based on the first two Waves by allowing potential confounding variables to be determined at a time before vaping started. Whereas the earlier analyses suggested that the adjustment for confounding explained about $80 \%$ of the unadjusted relationship between vaping and subsequent initiation of smoking, our current analyses suggest that adjustment explains only about $50 \%$. This provides stronger evidence of a true effect of vaping, although doubt still remains about its true magnitude for reasons discussed.

\section{Data availability}

Underlying data

National Addiction \& HIV Data Archive Program: Population Assessment of Tobacco and Health (PATH) Study [United States] Public-Use Files (ICPSR 36498). https://doi. org/10.3886/ICPSR36498.v9 (United States Department of Health and Human Services (USDHHS), 2019).

The data are available under the Terms of Use as set out by ICPSR, which can be accessed when users start the process of downloading the data.

\section{Extended data}

Open Science Framework: Further investigation of gateway effects using the PATH study https://doi.org/10.17605/OSF. IO/7ECQH (Lee, 2020).

This project contains the following extended data files:

- Gateway paper for F1000 Research_Additional file.docx

Data are available under the terms of the Creative Commons Zero "No rights reserved" data waiver (CC0 1.0 Public domain dedication).

\section{Acknowledgements}

We thank Esther Afolalu for assistance in acquiring the data from the PATH study, and Zheng Sponsiello-Wang and Christelle Chrea for providing technical comments at various stages. We also thank Jan Hamling for assistance in running the analyses, and Yvonne Cooper and Diana Morris for typing the various drafts of the paper.
Barrington-Trimis JL, Urman R, Leventhal AM, et al.: E-cigarettes, cigarettes, and the prevalence of adolescent tobacco use. Pediatrics. 2016; 138(2): e20153983. PubMed Abstract | Publisher Full Text | Free Full Text

Best C, van der Sluijs W, Haseen F, et al:: Does exposure to cigarette brands increase the likelihood of adolescent e-cigarette use? A cross-sectional study. BMJ Open. 2016; 6(2): e008734.

PubMed Abstract | Publisher Full Text | Free Full Text

Bold KW, Kong G, Camenga DR, et al.: Trajectories of e-cigarette and

conventional cigarette use among youth. Pediatrics. 2018; 141(1): e20171832.

PubMed Abstract | Publisher Full Text | Free Full Text
Chien YN, Gao W, Sanna M, et al.: Electronic cigarette use and smoking initiation in Taiwan: Evidence from the First Prospective Study in Asia. Int J Environ Res Public Health. 2019; 16(7): 1145.

PubMed Abstract | Publisher Full Text | Free Full Text

East K, Hitchman SC, Bakolis I, et al.: The association between smoking and electronic cigarette use in a cohort of young people. J Adolesc Health. 2018; 62(5): 539-547.

PubMed Abstract | Publisher Full Text | Free Full Text

Kinnunen JM, Ollila H, Minkkinen J, et al.: Nicotine matters in predicting subsequent smoking after e-cigarette experimentation: A longitudinal study 
among Finnish adolescents. Drug Alcohol Depend. 2019; 201: 182-187. PubMed Abstract | Publisher Full Text

Lee P: Further Investigation of Gateway Effects Using the PATH Study. OSF. 2020.

http://www.doi.org/10.17605/OSF.IO/7ECQH

Lee P, Fry J: Investigating gateway effects using the PATH study [version 2; peer review: 2 approved]. F1000Res. 2019; 8: 264.

PubMed Abstract | Publisher Full Text | Free Full Text

Lee PN, Coombs KJ, Afolalu EF: Considerations related to vaping as a possible gateway into cigarette smoking: an analytical review [version 3; peer review: 2 approved]. F1000Res. 2018; 7: 1915.

PubMed Abstract | Publisher Full Text | Free Full Text

Miech R, Johnston L, O'Malley PM, et al.: Trends in adolescent vaping, 2017-

2019. N Engl J Med. 2019; 381(15): 1490-1491.

PubMed Abstract | Publisher Full Text

Morgenstern M, Nies A, Goecke M, et al:: E-Cigarettes and the use of

conventional cigarettes. Dtsch Arztebl Int. 2018; 115(14): 243-248.

PubMed Abstract | Publisher Full Text | Free Full Text

National Academies of Sciences Engineering and Medicine: Public health

consequences of e-cigarettes. The National Academies Press, Washington DC.

2018.

Publisher Full Text

Nutt DJ, Phillips LD, Balfour D, et al.: Estimating the harms of nicotine-containing products using the MCDA approach. Eur Addict Res. 2014; 20(5): 218-225. PubMed Abstract | Publisher Full Text

Pénzes M, Foley KL, Nadasan V, et al.: Bidirectional associations of e-cigarette, conventional cigarette and waterpipe experimentation among adolescents: $\mathbf{A}$ cross-lagged model. Addict Behav. 2018; 80: 59-64.

PubMed Abstract | Publisher Full Text | Free Full Text

Primack BA, Shensa A, Sidani JE, et al.: Initiation of traditional cigarette

smoking after electronic cigarette use among tobacco-naive US young adults.

Am J Med. 2018; 131(4): 443.e1-443.e9.

PubMed Abstract | Publisher Full Text | Free Full Text

Soneji S, Barrington-Trimis JL, Wills TA, et al.: Association between initial use of e-cigarettes and subsequent cigarette smoking among adolescents and young adults: A systematic review and meta-analysis. JAMA Pediatr. 2017; 171(8):

788-797.

PubMed Abstract | Publisher Full Text | Free Full Text

Treur JL, Rozema AD, Mathijssen JJP, et al.: E-cigarette and waterpipe use in two adolescent cohorts: cross-sectional and longitudinal associations with conventional cigarette smoking. Eur J Epidemiol. 2018; 33(3): 323-334.

PubMed Abstract | Publisher Full Text | Free Full Text

United States Department of Health and Human Services (USDHHS): Population assessment of tobacco and health (PATH) Study [United States] Public-Use Files (ICPSR 36498-V9). 2019

Publisher Full Text 


\title{
Open Peer Review
}

\section{Current Peer Review Status: ? ?}

\section{Version 1}

Reviewer Report 13 October 2020

https://doi.org/10.5256/f1000research.26798.r71761

(c) 2020 Xu S. This is an open access peer review report distributed under the terms of the Creative Commons Attribution License, which permits unrestricted use, distribution, and reproduction in any medium, provided the original work is properly cited.

\author{
Shu Xu \\ ${ }^{1}$ Department of Biostatistics, NYU School of Global Public Health, New York City, NY, USA \\ 2 New York University, New York, NY, USA
}

The authors examined the association between youth prior e-cigarette use and increased risk of subsequent cigarette smoking using the Waves 1 - 3 data from the PATH study. This work is an extension of their previous studies which were published in Lee et al. (2018) and Lee and Fry (2019), the latter was based on the Waves 1 and 2 data from the PATH study. This study is interesting because the authors conducted three main analyses studying the association between e-cigarette use and subsequent cigarette smoking along with sensitivity analyses. This review emphasized the statistical methodology and results reporting. A few major concerns are below.

1. I feel the readability of this paper would be improved if authors could (1) focus on what is the limitation of the previous articles, (2) clearly state what are the new analyses about based on what has been done previously, and (3) state why versions of M1, M2, M3 were conducted and the logic behind them. The authors need to provide a full picture of the study design and analytical plan of the current study. In case some details are overlapped with previous articles when referred to the previous article, authors need to at least summarize the details instead of releasing no specific information.

2. The main concern of the previous study is about the possibility of "over-adjustment," and the extent to which the association between prior e-cigarette use and subsequent cigarette initiation has been "over-adjusted." It would be critical to evaluate whether covariate balance was sufficient when propensity scores had been considered in the current analyses. Without covariate balance, the results of the current study may be considered unreliable. Thus, detailed results such as (a) propensity score distribution by e-cigarette exposure groups and (b) comparison of the extent of covariate imbalance are desired.

3. In the Methods section, authors need to clearly state how the missing values were treated in analyses of the current study. This also involved how authors treated the missing values when selecting covariates of versions of $M 1, M 2$, and $M 3$. The results of the current study could be misleading if only participants with complete data were considered. 
4. It was unclear to me why to study the continuous age and grouped age and compare the difference. It seems like continuous age provided an exact measure however grouped age did not. Putting participants into categories is rarely defensible unless authors provide further justification. It is also unclear to me why only interactions with age (no other covariates, for example, race) were considered.

Minor concerns are below.

1. In tables, in addition to individuals who were 16-17 at Wave 1, adult data were used. Please clarify, for those who were 15-16 at Wave 1 (those who were 18+ at Wave 3), whether adult data were also used in this study?

2. The abstract was very confusing. It failed to provide an overview of the study. For example, a clear introduction of the methods and results of $\mathrm{M} 1$ and have been presented. This information regarding $\mathrm{M} 2$ and $\mathrm{M} 3$ were not clearly reported.

Is the work clearly and accurately presented and does it cite the current literature? Yes

Is the study design appropriate and is the work technically sound? Partly

Are sufficient details of methods and analysis provided to allow replication by others? Partly

If applicable, is the statistical analysis and its interpretation appropriate? Partly

Are all the source data underlying the results available to ensure full reproducibility? Yes

Are the conclusions drawn adequately supported by the results? Yes

Competing Interests: No competing interests were disclosed.

Reviewer Expertise: Longitudinal data analysis, propensity score methods, missing data method, tobacco research.

I confirm that I have read this submission and believe that I have an appropriate level of expertise to confirm that it is of an acceptable scientific standard, however I have significant reservations, as outlined above.

Author Response 28 Oct 2020

Peter Lee

Reply to comments made by Shu Xu 
We thank the reviewer for the time he has spent and the useful comments made. Our replies to the points made are given in bold face type, making it clear where we have amended the original version of the paper. Note that the changes made to the paper are also intended to answer the points made by James Sargent, the other reviewer. We hope that our answers and the changes to the paper will allow the revision to be approved.

Approved With Reservations

The authors examined the association between youth prior e-cigarette use and increased risk of subsequent cigarette smoking using the Waves 1 - 3 data from the PATH study. This work is an extension of their previous studies which were published in Lee et al. (2018) and Lee and Fry (2019), the latter was based on the Waves 1 and 2 data from the PATH study. This study is interesting because the authors conducted three main analyses studying the association between e-cigarette use and subsequent cigarette smoking along with sensitivity analyses. This review emphasized the statistical methodology and results reporting. A few major concerns are below.

I feel the readability of this paper would be improved if authors could (1) focus on what is the limitation of the previous articles, (2) clearly state what are the new analyses about based on what has been done previously, and (3) state why versions of M1, M2, M3 were conducted and the logic behind them. The authors need to provide a full picture of the study design and analytical plan of the current study. In case some details are overlapped with previous articles when referred to the previous article, authors need to at least summarize the details instead of releasing no specific information.

The three paragraphs of the discussion starting "Our second paper.." describe in some detail the analyses we had previously conducted using data from Waves 1 and 2 only, what the main results of these analyses were, and the fact that the estimates were open to the possibility of over-adjustment if taking up e-cigarettes had affected the values of some of the Wave 1 predictor variables considered. It also makes it clear that our earlier paper described how this possibility could be avoided by using data from Waves 1, 2 and 3. We have now amended the final paragraph of the discussion to make it clear that analysis M1 in the current paper was that envisaged in our earlier paper, and that this was the main objective of our work. In the methods section, there was already some comment on why we had conducted the other main analyses, the sensitivity analyses and the alternative analyses, but this has now been extended in various places to make it clearer. Where details of our analyses are the same as those in our earlier analyses, it seems needlessly duplicative to repeat these details in the current paper, and is not the usual thing to do in such a situation.

The main concern of the previous study is about the possibility of "over-adjustment," and the extent to which the association between prior e-cigarette use and subsequent cigarette initiation has been "over-adjusted." It would be critical to evaluate whether covariate balance was sufficient when propensity scores had been considered in the current analyses. Without covariate balance, the results of the current study may be considered unreliable. Thus, detailed results such as (a) propensity score distribution by e-cigarette exposure groups and (b) comparison of the extent of covariate imbalance are desired. 
Our latest paper has removed the possibility of over-adjustment in our previous work by the use of propensity indicators based on data recorded at Wave 1 in those who, at that time, had never vaped. The reviewer questions whether covariate balance is sufficient after the propensity scores are taken into account. This has been investigated in Tables 2, 3 and 4 for the three main analyses in turn by considering whether adjustment for the individual variables making up the propensity index materially affected the estimated gateway effect. The effect was generally quite small, suggesting that reasonable balance had been achieved. We think that including the additional material suggested by the reviewer would add little other than extra complexity. We also note that our previous paper did not include such material and was approved by the reviewers who considered it.

In the Methods section, authors need to clearly state how the missing values were treated in analyses of the current study. This also involved how authors treated the missing values when selecting covariates of versions of $M 1, M 2$, and $M 3$. The results of the current study could be misleading if only participants with complete data were considered.

As we note in the first sentence of the methods section "Some aspects of the analyses described here are the same as those described earlier (Lee \& Fry, 2019) are not presented again here." In that paper we made it clear that all the logistic regression analyses used "required individuals with complete data on all variables", and that the various stages in developing propensity scores used "groups of conceptually-related variables, with missing values likely to be on the same individuals". We prefer not to repeat the description of this part of the methodology in the current paper. However, in the new paragraph we have added into the discussion (starting "Other issues are..."), we have addressed your point that basing the analysis only on complete data might be misleading. This point is similar to one raised by another reviewer. We hope you find this satisfactory.

It was unclear to me why to study the continuous age and grouped age and compare the difference. It seems like continuous age provided an exact measure however grouped age did not. Putting participants into categories is rarely defensible unless authors provide further justification.

As regards age, the 2019 paper we had published based only on Wave 1 and 2 subdivided individuals into ages 12-14 and 15-17 as the data were only available in that form. Assuming that the Waves were conducted a year apart (which they approximately were) we could infer that those who were 12-14 at Wave 1 and 15-17 at Wave 2 were 14 at Wave 1 (and 15 at Wave 2), and that those who were 15-17 at Wave 1 and adults at Wave 2 were 17 at Wave 1 (and 18 at Wave 2). However we could not estimate the exact age of those who were 12,13, 15 or 16 at Wave 1 . The position changed in the analyses using Wave 3 as well, as we could define those who were 1214 throughout as 12 at Wave 1, those who were 12-14 at Waves 1 and 2 and 15-17 at Wave 2 as 13 at Wave 1 and so on. While it would be preferable to use exact age throughout in some ways, here we were carrying out further analyses using the propensity index developed in the 2019 paper which included a term based on grouped age. As the paper presents the main analyses using both grouped age and exact age, and the results were much the same, there is no real problem.

It is also unclear to me why only interactions with age (no other covariates, for example, race) were considered. 
On the basis that age had a major effect on the rate of e-cigarette use and on uptake of smoking, we included interactions of age with the three predictors most strongly linked to the relevant gateway effect. As this had essentially no effect on the estimates of the gateway effect, we felt that looking at further interactions would not be worthwhile. Race was not a predictor that was included in the propensity index, so it seemed highly unlikely that including interactions with it would have had any major effect. It would of course have been theoretically possible to consider many more predictors, including interactions of each predictor with each other predictor, higher order interactions, or quadratic or cubic terms in some predictors, but one has to stop somewhere. However in the third paragraph of the discussion we have changed "there may be some relevant predictors not considered" to "there may be some relevant predictors or interactions of predictors not considered."

Minor concerns are below.

In tables, in addition to individuals who were 16-17 at Wave 1, adult data were used. Please clarify, for those who were 15-16 at Wave 1 (those who were 18+ at Wave 3), whether adult data were also used in this study?

Those who were 17 at Wave 1 would have been 18 at Wave 2 so adult data would have been used. Similarly, those who were 16 at Wave 1 would have been 18 at Wave 3 so adult data would again have been used. However, those who were 15 at Wave 1 would not have been adults at Wave 3 , so adult data were irrelevant. To avoid confusion we have changed age ranges like "16-17" to "16 or 17" in the various places they occurred in the paper.

The abstract was very confusing. It failed to provide an overview of the study. For example, a clear introduction of the methods and results of $\mathrm{M} 1$ and have been presented. This information regarding M2 and M3 were not clearly reported.

We are constrained by the $\mathbf{3 0 0}$ word limit for the abstract, but have modified the abstract (particularly the methods section) to try to make things clearer.

Is the work clearly and accurately presented and does it cite the current literature?

Yes

Is the study design appropriate and is the work technically sound?

Partly

Are sufficient details of methods and analysis provided to allow replication by others?

Partly

If applicable, is the statistical analysis and its interpretation appropriate?

Partly

Are all the source data underlying the results available to ensure full reproducibility?

Yes

Are the conclusions drawn adequately supported by the results?

Yes

I confirm that I have read this submission and believe that I have an appropriate level of expertise to confirm that it is of an acceptable scientific standard, however I have significant reservations, as outlined above.

We hope that we have answered the reviewer's reservations adequately. 
Competing Interests: The authors are both long term consultants to the tobacco industry

Reviewer Report 22 July 2020

https://doi.org/10.5256/f1000research.26798.r66520

(C) 2020 Sargent J. This is an open access peer review report distributed under the terms of the Creative Commons Attribution License, which permits unrestricted use, distribution, and reproduction in any medium, provided the original work is properly cited.

\section{James Sargent}

C. Everett Koop Institute, Norris Cotton Cancer Center, Geisel School of Medicine at Dartmouth, Lebanon, $\mathrm{NH}$, USA

This is a thoughtful analysis of PATH data to determine an unbiased estimate of the relation between initial e-cigarette use among never cigarette smokers and subsequent cigarette smoking. I particularly like the idea of using W1 predictors of W2 e-cigarette onset to parcel out the over adjustment that could occur if these variables are assessed at the same time. I also liked the multitude of sensitivity analyses that showed it doesn't really matter, for example, how propensity scores are modeled. I see no major weaknesses. However I have a few suggestions.

1. It might not be unreasonable to have a statistician review the analysis.

2. This is a complete case analysis. Given that there are missing data for each individual variable and that there is loss to follow up, the authors need to convince us with some sort of sensitivity analysis that the results are not largely affected by attrition bias.

3. The literature review makes it seem like these are the only authors who have published on gateway effects using PATH data. They need to cite other PATH papers, point out weaknesses in them, and help us understand why this publication is worthy of attention. One worthy of particular attention used a propensity score analysis similar to these authors' W1-W2 analysis ${ }^{1}$

4. One limitation not mentioned is that cigarette smoking onset does not make addicted cigarette smoker. This needs to be mentioned as a limitation.

5. The authors miss some of the many studies that examined the relation between initial use of e-cigarettes and subsequent cigarette smoking. They could fill in that gap by mentioning and citing a meta-analysis conducted by Khouja in Tobacco Control that identified 17 prospective studies ${ }^{2}$. It is worth comparing their best estimate with the combined estimates presented in that meta analysis.

6. Finally, given that there have been so many prospective studies, and all have pointed to a gateway effect, it seems reasonable to conclude that there is one, that is, that use of these devices independently increases risk for subsequent use of cigarettes. I realize that we 
could continue to quibble about the effect size, but this study does a good job of convincing us that the relative risk is real and that it is substantial, around 3. It seems like it might be an opportunity to also help us understand the population significance of the finding. The authors could do that with this population-based sample (which includes weights) by determining what proportion of the observed cigarette initiation is attributable to the gateway effect using attributable risk methods (risk difference as opposed to risk ratio). They could use the weights to determine the number of new cigarette initiators there were in the US that year attributable to e-cigarette exposure. This would be a real and novel contribution that would help investigators compare the public health consequences to youth with the public health consequences resulting from increased smoking cessation.

\section{References}

1. Stanton C, Bansal-Travers M, Johnson A, Sharma E, et al.: Longitudinal e-Cigarette and Cigarette Use Among US Youth in the PATH Study (2013-2015). JNCI: Journal of the National Cancer Institute. 2019; 111 (10): 1088-1096 Publisher Full Text

2. Khouja JN, Suddell SF, Peters $S E$, Taylor $A E$, et al.: Is e-cigarette use in non-smoking young adults associated with later smoking? A systematic review and meta-analysis.Tob Control. 2020. PubMed Abstract | Publisher Full Text

Is the work clearly and accurately presented and does it cite the current literature? Yes

Is the study design appropriate and is the work technically sound? Yes

Are sufficient details of methods and analysis provided to allow replication by others? Yes

If applicable, is the statistical analysis and its interpretation appropriate?

I cannot comment. A qualified statistician is required.

Are all the source data underlying the results available to ensure full reproducibility? Yes

Are the conclusions drawn adequately supported by the results? Yes

Competing Interests: No competing interests were disclosed.

Reviewer Expertise: Adolescent substance use.

I confirm that I have read this submission and believe that I have an appropriate level of expertise to confirm that it is of an acceptable scientific standard, however I have significant reservations, as outlined above. 


\section{Peter Lee}

Reply to comments made by James Sargent

We thank the reviewer for the time he has spent and the useful comments made. Our replies to the points made are given in bold face type, making it clear where we have amended the original version of the paper. Note that the changes made to the paper are also intended to answer the points made by Shu $\mathrm{Xu}$, the other reviewer. We hope that our answers and the changes to the paper will allow the revision to be approved.

Approved With Reservations

This is a thoughtful analysis of PATH data to determine an unbiased estimate of the relation between initial e-cigarette use among never cigarette smokers and subsequent cigarette smoking. I particularly like the idea of using W1 predictors of W2 e-cigarette onset to parcel out the over adjustment that could occur if these variables are assessed at the same time. I also liked the multitude of sensitivity analyses that showed it doesn't really matter, for example, how propensity scores are modeled. I see no major weaknesses. However I have a few suggestions.

It might not be unreasonable to have a statistician review the analysis.

Both the authors of this paper are experienced statisticians, as is Shu $\mathrm{Xu}$, the other reviewer.

This is a complete case analysis. Given that there are missing data for each individual variable and that there is loss to follow up, the authors need to convince us with some sort of sensitivity analysis that the results are not largely affected by attrition bias.

We have added a new paragraph into the discussion, starting "Other issues are..." and hope this meets the reviewer's point.

The literature review makes it seem like these are the only authors who have published on gateway effects using PATH data. They need to cite other PATH papers, point out weaknesses in them, and help us understand why this publication is worthy of attention. One worthy of particular attention used a propensity score analysis similar to these authors' W1-W2 analysis ${ }^{1}$.

We have added a new paragraph in the discussion, after the one referring to other studies on the gateway issue, to consider other studies using PATH data, including the Watkins study on which we had commented previously in our 2019 paper.

One limitation not mentioned is that cigarette smoking onset does not make addicted cigarette smoker. This needs to be mentioned as a limitation.

At the end of the paragraph in the discussion starting "Generally our consistent" we have made the point that some of those recorded as taking up smoking at Wave 3 may only have taken it up for a short while, a limitation that can be answered better in analyses based also on data from later Waves.

The authors miss some of the many studies that examined the relation between initial use of e-cigarettes and subsequent cigarette smoking. They could fill in that gap by mentioning and citing a meta-analysis conducted by Khouja in Tobacco Control that identified 17 prospective studies $^{2}$. It is worth comparing their best estimate with the combined estimates presented in that meta analysis.

We are not sure why the reviewer thought we were not citing other studies. The first 
paragraph of the introduction refers to the meta-analysis of Soneji et al. which considered nine studies, while the second paragraph of the introduction refers to our 2018 paper which includes a detailed commentary on 15 studies. Also the fourth paragraph of the discussion refers to quite a number of recent studies. However, we have now made it clear in the paragraph summarizing conclusions from our 2018 paper that it considered $\mathbf{1 5}$ cohort studies that have reported unadjusted and

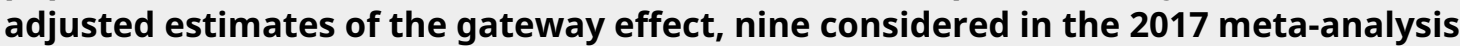
by Soneji et al. and six additional studies. We have also added a paragraph in the introduction mentioning the recent review by Khouja et al. that the reviewer referred to.

Finally, given that there have been so many prospective studies, and all have pointed to a gateway effect, it seems reasonable to conclude that there is one, that is, that use of these devices independently increases risk for subsequent use of cigarettes. I realize that we could continue to quibble about the effect size, but this study does a good job of convincing us that the relative risk is real and that it is substantial, around 3. It seems like it might be an opportunity to also help us understand the population significance of the finding. The authors could do that with this population-based sample (which includes weights) by determining what proportion of the observed cigarette initiation is attributable to the gateway effect using attributable risk methods (risk difference as opposed to risk ratio). They could use the weights to determine the number of new cigarette initiators there were in the US that year attributable to e-cigarette exposure. This would be a real and novel contribution that would help investigators compare the public health consequences to youth with the public health consequences resulting from increased smoking cessation.

In order to illustrate the population effect we have added a new paragraph in the discussion (starting "A question of interest is..") which estimates the percentage of new smokers associated with exposure to e-cigarettes as about $23 \%$.

Is the work clearly and accurately presented and does it cite the current literature?

Yes

Is the study design appropriate and is the work technically sound?

Yes

Are sufficient details of methods and analysis provided to allow replication by others?

Yes

If applicable, is the statistical analysis and its interpretation appropriate?

I cannot comment. A qualified statistician is required.

See comment above.

Are all the source data underlying the results available to ensure full reproducibility?

Yes

Are the conclusions drawn adequately supported by the results?

Yes

References

1. Stanton C, Bansal-Travers M, Johnson A, Sharma E, et al.: Longitudinal e-Cigarette and 
Cigarette Use Among US Youth in the PATH Study (2013-2015). JNCI: Journal of the National Cancer Institute. 2019; 111 (10): 1088-1096 Publisher Full Text

2. Khouja JN, Suddell SF, Peters SE, Taylor AE, et al.: Is e-cigarette use in non-smoking young adults associated with later smoking? A systematic review and meta-analysis.Tob Control. 2020. PubMed Abstract | Publisher Full Text

I confirm that I have read this submission and believe that I have an appropriate level of expertise to confirm that it is of an acceptable scientific standard, however I have significant reservations, as outlined above.

We hope that we have answered the reviewer's reservations adequately.

Competing Interests: The authors are both long term consultants to the tobacco industry

The benefits of publishing with F1000Research:

- Your article is published within days, with no editorial bias

- You can publish traditional articles, null/negative results, case reports, data notes and more

- The peer review process is transparent and collaborative

- Your article is indexed in PubMed after passing peer review

- Dedicated customer support at every stage

For pre-submission enquiries, contact research@f1000.com 